\title{
Effect of Application of UV Irradiated Beauveria bassiana and Metarhizium anisopliae on Larval Weight and Mortality of Spodoptera litura
}

\author{
Siti Herlinda ${ }^{1,2^{*}}$, Sangkut Sri Oktareni ${ }^{1}$, Suparman $^{1}$, Erise Anggraini ${ }^{1,2}$, Elfita $^{3}$, Arum \\ Setiawan $^{3}$, Marieska Verawaty ${ }^{3}$, Hasbi $^{1,2}$, Benyamin Lakitan ${ }^{1,2}$ \\ ${ }^{1}$ Faculty of Agriculture, Universitas Sriwijaya, Indralaya, Indonesia \\ ${ }^{2}$ Research Center for Sub-optimal Lands (PUR-PLSO), Universitas Sriwijaya, Palembang, Indonesia \\ ${ }^{3}$ Faculty of Mathematics and Natural Sciences, Universitas Sriwijaya, Indralaya, Indonesia \\ *Corresponding author. Email: sitiherlinda@ unsri.ac.id
}

\begin{abstract}
Entomopathogenic fungi have been widely used to control insect pests. The objective of this experiment was to find out the insecticidal activity of filtrate of entomopathogenic fungal cultures exposed to ultra violet (UV) $\mathrm{C}$ against the larvae of Spodoptera litura. The fungi used were Beauveria bassiana and Metarhizium anisopliae and their liquid cultures exposed to $\operatorname{UV} C(5,10,15,20$, and 30 watts) for 6 hours. The results showed that the larva mortality caused by $B$. bassiana culture filtrate without irradiation was the highest (97.3\%) and significantly different from those caused by M. anisopliae culture filtrate (96.0\%). However, the mortality caused by $B$. bassiana culture filtrate irradiated with UV C decreased significantly compared to the mortality caused by $M$. anisopliae culture filtrate irradiated by UV C. LT $_{50}$ of the filtrate of $M$. anisopliae culture irradiated with UV C was 10.51 days and was significantly shorter than those of B. bassiana (18.09 days). Thus, the M. anisopliae was more resistant to irradiation compared to B. bassiana.
\end{abstract}

Keywords: Beauveria bassiana, insect pests, $L T_{50}$, Metarhizium anisopliae, mortality

\section{INTRODUCTION}

Freshwater swamps in Indonesia are about 9.2 Mha [1] and the land is flooded more than 6 months every year [2]. Such condition makes the soil can be planted only with specific crops that adapt to the wet conditions [3, 4]. In the dry season, farmers generally cultivate rice [5], while others cultivate several vegetables, such as cucumber, bittermelon, yard long beans, ridge gourd [3], and chilli [6].

Chilli is a dominant vegetable crop cultivated in freshwater swamp. The main problem on chilli crop is pest attack such as Spodoptera litura [7], thrips [6, 8], and fruit flies [9]. An approach to reduce the population and pest attacks environmentally friendly and to produce healthy chili products is by utilizing a bio-control agents [10], i.e the use of entomopathogenic fungi. The entomopathogenic fungi have been known to be effective to various species of insect pests, such as Beauveria bassiana [11, 12] and Metarhizium anisopliae [13, 14]. B. bassiana culture filtrate can cause mortality up to $100 \%$ of Spodoptera litura larvae [11]. The effectiveness of culture filtrate is influenced by many environmental factors, hence further study needs to be conducted. The previous studies showed that light and sunlight, temperature, and humidity can affect the effectiveness of the fungi filtrate $[15,16]$.
Blazing sunlight can kill the fungi [17]. Short waves produced by ultraviolet (UV) radiation have been proven to reduce the viability of the entomopathogenic fungi conidia [18] and even kill the fungi [15]. The UV-B radiation at $6153.3 \mathrm{~mW} \cdot \mathrm{m}^{-2}$ exposed for 5 minutes could decrease the germination of B. bassiana and M. anisopliae conidia from $94 \%$ to $52 \%$ and $96 \%$ to $54 \%$, respectively [17]. Radiation of UV-B at $978 \mathrm{~mW} \cdot \mathrm{m}^{-2}$ could cause several isolates of B. bassiana to be tolerant [19]. Thus, the tolerant isolates will be superior and can be developed and applied to the field. The aim of this research was to study the effect of an insecticidal activity of filtrate of entomopathogenic fungal cultures irradiated with ultra violet (UV) C on the larvae of S. litura.

\subsection{Materials and Methods}

This study was conducted at the Entomology Laboratory, Department of Pests and Plant Diseases, Faculty of Agriculture, Sriwijaya University from May to November 2018. The average temperature during the bioassay was $29.78^{\circ} \mathrm{C}$ and relative humidity was $82.72 \%$. The isolates used in this study were explored by Safitri et al. (2018), namely B. bassiana with BSwTd2 code obtained from oil palm peat soil in Talang Dabok and M. anisopliae 
coded MKbTp2 obtained from the highland cabbage soil in Talang Patai. Each isolate was treated with UV C irradiation with wavelengths ranged from 200-280 nm. Factorial Randomized Block Design with the first factor of 2 species of the fungi and the second factor of irradiation intensity was used. The mortality and weight data were presented in Tables 1-3.

\subsubsection{Test insect preparation}

The test insect in this experiment was S. litura. The larvae and eggs were collected from the synthetic pesticides-free chili crops in the experimental field of the Faculty of Agriculture, Sriwijaya University.The larvae were fed with chili leaves in a plastic cage $(30 \mathrm{~cm}$ high $\mathrm{x} 25$ $\mathrm{cm}$ in diameter) covered with gauze and the feed was replaced daily. When approaching the pupae stage, the last instar larvae were placed into a plastic cage containing $3 \mathrm{~cm}$ thick sterilized soil. Then, the pupae were transferred into an insect cage. The eggs of S. litura were collected by placing chilli plant. The eggs laid on the chilli leaves were transferred into the plastic cage which already provided with fresh chili leaves for feeding the newly hatched larvae. The mass rearing was carried out until getting a second generation of larvae. The third generation of the second 1day-old instar was used as test insects in this experiment.

\subsubsection{Preparation of the entomopathogenic fungi and production of culture filtrate}

Sabouraud Dextrose Agar (SDA) medium enriched with Tenebrio molitor flour was used to increase fitness of $B$. bassiana and M. anisopliae isolates Herlinda method [10]. As many as $16.2 \mathrm{~g}$ of SDA medium was added with $250 \mathrm{ml}$ of distilled water, then mixed with $1 \mathrm{~g}$ of $T$. molitor flour which had been sterilized at $100^{\circ} \mathrm{C}$ for 4 hours. Each culture isolate of $1 \times 1 \mathrm{~cm}^{2}$ of the 21 days-old SDA medium (Figure 1) was grown in SDB (Sabouraud Dextrose Broth) medium. The SDB medium was prepared in advance with as many as $30 \mathrm{~g}$ added $1000 \mathrm{ml}$ distilled water. Then, the liquid culture (culture broth) fungi was incubated for 6 weeks (Figure 2). The culture broth for each isolate of the SDB medium was then filtered to separate the culture or supernatant filtrate from the pellets (hyphae, mycelia, and conidia/spore) through two stages using the Cheong method
(2015). A total of $100 \mathrm{ml}$ culture broth on SDB was filtered into the erlenmeyer flask (500 ml volume) using Whatman No. 42 filter paper covered with $1 \mathrm{~cm}$ thick cotton to produce $\pm 70 \mathrm{ml}$ of crude culture filtrate. Then, the crude filtrate culture was filtered using a syringe filter $(0.45 \mu \mathrm{m}$ $25 \mathrm{~mm}$ ). The filtering with a syringe filter was carried out by means of $1 \mathrm{ml}$ of crude culture filtrate drawn using a hypodermic needle (volume $6 \mathrm{ml}$ ). The needle was removed and the base of the needle was attached to a syringe filter. Then, the needle was refitted to the hypodermic needle and the $1 \mathrm{ml}$ of the crude filtrate was filtered using a syringe filter to obtain culture filtrate (Figure 3 ).

The culture filtrates were poured into Petri dish $(9 \mathrm{~cm}$ in diameter). Then, each isolate was illuminated for 6 hours using UV $\mathrm{C}$ at $0,5,10,15,20$, and 30 watts $(=0,5000$, $10000,15000,20000$, and $30000 \mathrm{~mW} . \mathrm{m}^{-2}$ ), and control without the fungi (distilled water). The distance between the light source and the Petri dish was $12.5 \mathrm{~cm}$ (Figure 4).

\subsubsection{Bioassays for assessing insecticidal activity of the culture filtrates}

The irradiated culture filtrates were tested for their insecticidal activity against the second instar of $S$. litura larvae. As many as 5 pieces of chili leaves were dipped with the pure culture filtrate and then air-dried at room temperature. The air-dried chili leaves were put into a plastic cylinder whose top was covered with gauze $(9.5 \mathrm{~cm}$ in diameter and $15.5 \mathrm{~cm}$ high), after that the 25 unfed larvae for 24 hours were introduced into the plastic cylinder. After 6 hours, the 25 larvae were transferred to another plastic cylinder containing 10 pieces of fresh leaves. Chilli leaves were replaced daily. The dead larvae were recorded and the larvae body was weighed every day for 13 days.

\subsubsection{Data analysis}

The larva mortality and weight data were analysed using analysis of variance (ANOVA) and presented in Tables 13. The Least Significant Difference (LSD) Test was employed to test for significant differences between treatments (isolates) at $\mathrm{P}=0.05 . \mathrm{LT}_{50}$ values were calculated by using probit analysis. All data were analysed using SAS University Edition software 2.7 9.4 M5.

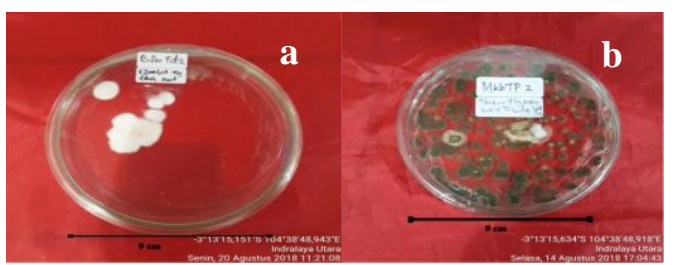

Figure 1 Agar culture of Beauveria bassiana (a) and Metarhizium anisopliae (b) in the SDA medium 

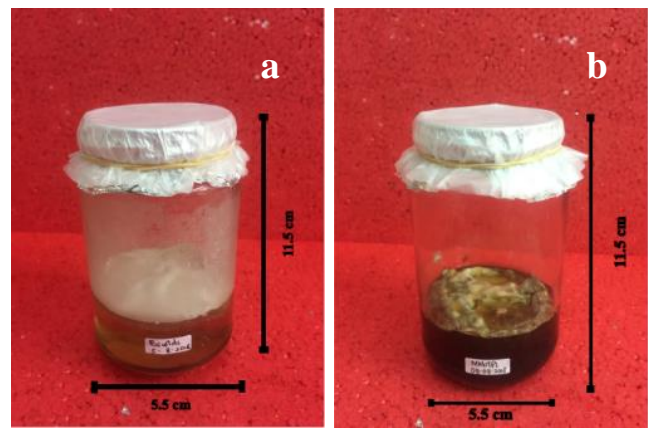

Figure 2 Broth culture of Beauveria bassiana (a) and Metarhizium anisopliae (b) in the SDB medium
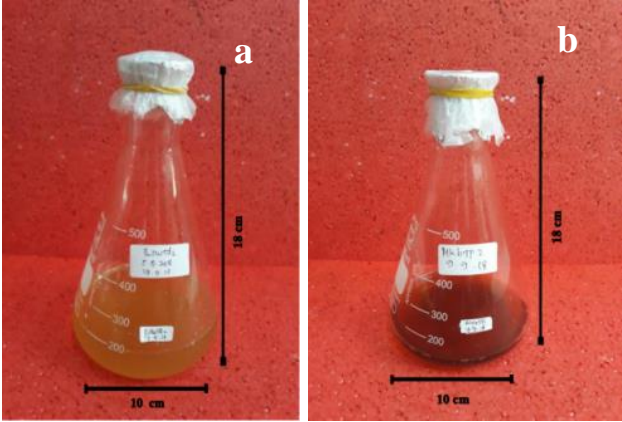

Figure 3 Culture filtrate of Beauveria bassiana (a) and Metarhizium anisopliae (b)

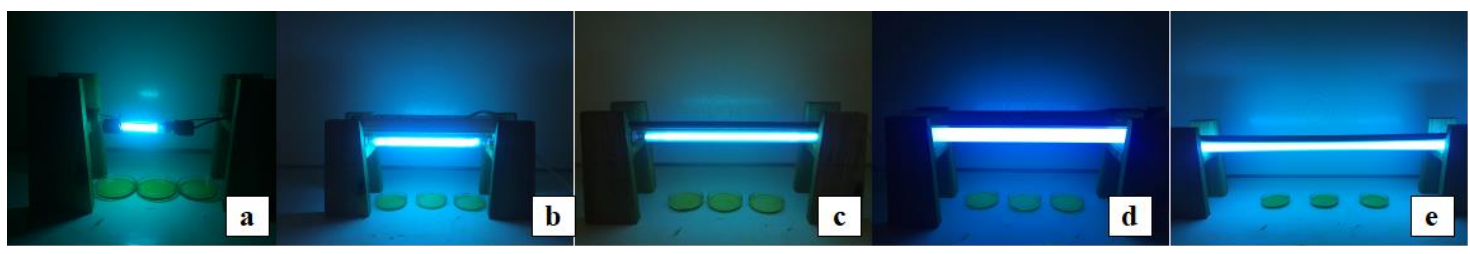

Figure 4 The radiation treatment 5 watts (a), 10 watts (b), 15 watts (c), 20 watts (d), and 30 watts (e)

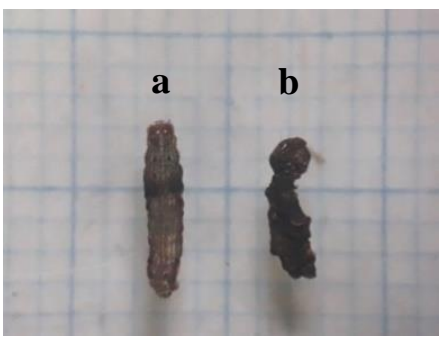

Figure 5 The healthy larvae of Spodoptera litura (a) and the dead one (b) caused by Beauveria bassiana culture filtrate (b)

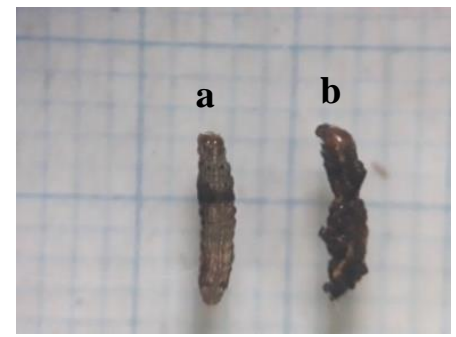

Figure 6 The healthy larvae of Spodoptera litura (a) and the dead one (b) caused by Metarhizium anisopliae culture filtrate 


\subsection{Our Contribution}

This paper presents new information that the culture filtrate of $M$. anisopliae still caused the high mortality of $S$. litura larvae at the UV C irradiation of up to 30 watts for 6 hours. M. anisopliae could survive and was more tolerant of high irradiation intensity.

\subsection{Paper Structure}

The rest of the paper is organized as follows. Section 2 presents symptoms of $S$. litura larvae fed with the fungal culture-filtrate. Section 3 presents data of the effect of fungi on larvae weight. Section 4 shows the mortality of larvae and the time needed by $50 \%$ of dead larvae $\left(\mathrm{LT}_{50}\right)$ caused by fungal culture filtrate. Finally, Section 5 concludes the paper and presents direction for future research.

\section{RESULTS AND DISCUSSION}

The $S$. litura larvae fed with the culture-filtrate treated leaves showed similar symptoms. At a day after feeding, the movement of larvae was slower than larvae fed on the untreated leaves. The feeding activity of the larvae kept declining and the body began to shrink and dull. Two days later, the larvae bodies got shrivelled, wrinkled, hard, dry, increasingly dull and black, odourless and eventually died (Figures 5 and 6). Before the larvae died, they secreted green liquid. Such larvae then grown in SDA media, after 5 to 7 days there were found no hyphae, mycelia, or conidia of the fungal. Therefore, the death of the larvae did not cause by fungi.

The data of the effect of fungi on larvae weight showed that the weight was higher on that of the M. anisopliae treatment than the other treatments (Table 1). However, these data were higher because they were related to the initial weights of the larvae used in the M. anisopliae treatment, hence the data did not reflect the influence of fungal. The data showed that the older the larvae, the higher the weight were. Yet, after 11 days of application the larva weight began to decrease.

The intensity of irradiation (UV C) to the culture filtrate of fungi was significantly affected the larvae weight 13 days after fed with the culture-filtrate treated leaves. The culture filtrate without irradiation treatment $(0$ watt $)$ caused the larvae weight to drop significantly compared to the control treatment (Table 2). The culture filtrate was illuminated with irradiation intensities from 5 to 30 watt resulting in the larval weight which was not significantly different from the control using the distilled water. However, there were no significant interactions found between the fungus species and irradiation intensity.

The fungi species significantly affected the mortality of larvae and the time needed by $50 \%$ of dead larvae $\left(\mathrm{LT}_{50}\right)$. The larvae mortality caused by the culture filtrate of $M$. anisopliae was significantly higher than that of B. bassiana. The $\mathrm{LT}_{50}$ caused by the culture filtrate of $M$. anisopliae were significantly shorter than that of $B$. bassiana. Thus, the culture filtrate of $M$. anisopliae was more effective in killing the $S$. litura larvae.

The intensity of the culture filtrate of the fungi irradiation significantly affected the mortality and $\mathrm{LT}_{50}$ larvae of $S$. litura. The fungal filtrate exposed to 0 watt irradiation intensity caused the highest larva mortality $(96.66 \%)$ and was significant when compared to other treatments. In addition, $\mathrm{LT}_{50}$ was the shortest treatment (7.62 days) and was no significantly different from the other treatments.

Fungi species and radiation intensity significantly affected the mortality and $\mathrm{LT}_{50}$ larvae of $S$. litura (Table 3 ). $M$. anisopliae filtrate tended to be more tolerant of the intensity of irradiation when compared to B. bassiana, for example when exposed to 30 watts, the larvae mortality by M. anisopliae was $9.33 \%$, whereas that by $B$. bassiana was only $4 \%$. Likewise, the $\mathrm{LT}_{50}$ was affected by the species of fungi and irradiation intensity. For example, in 30-watt irradiation intensity, the $\mathrm{LT}_{50}$ larvae caused by $M$. anisopliae were shorter (17.67 days) than those caused by B. bassiana (42.66 days).

The $S$. litura larvae feeding on leaves applied to the culture filtrates of B. bassiana and M. anisopliae showed that the symptoms of the body got shrunken, contracted, dried, and odourless. According to Ayudya et al. (2019), the insect died due to the toxic compounds contained in the culture of filtrate fungi, not due to its conidia infection. The insects died due to the conidia fungi generally showed shrivelled and hard symptoms, and from the body of the host insects grew mycelia, hyphae, and conidia fungus on the surface of the insect integument [12], whereas in this study there were no mycelia, hyphae, and conidia fungus growing in the body of $S$. litura. Consequently, the $S$. litura larvae died due to the toxic compounds contained in the culture filtrate fungus.

The intensity of the culture filtrate irradiation significantly affected the larvae weight. The irradiation intensity of 0 watt caused the larvae weight to drop significantly due to the fact that the culture filtrate did not change so that it remained effective in reducing the larvae weight. However, if the culture filtrate was illuminated with an intensity of 5 to 30 watts, the larva weight was higher than that of 0 watt intensity. This higher larval weight indicated that the culture filtrate began to decrease in effectiveness. The culture filtrate was less able to reduce appetite of the larvae and they remained healthy with normal weight like those of treated with distilled water (control).

Although the irradiation of 5 to 30 watts against the culture filtrate of the fungi began to decrease the effectiveness of the fungi, the $M$. anisopliae was more tolerant of the UV C irradiation than B. bassiana. It is new information that the culture filtrate of $M$. anisopliae still caused the high mortality of $S$. litura larvae despite the UV C irradiation of up to 30 watts for 6 hours; the mortality still reached $9.33 \%$. M. anisopliae could survive and was more tolerant of high irradiation intensity because this fungus had a darker pigment which was more resistant to UV light than 
of the white fungus such as B. bassiana [20]. However, in the application of the entomopathogenic fungi in the field, it is still necessary to consider that the application should be carried out in the morning or evening when the sun does not shine brightly. The main problem in the utilization of the fungi is because of the low tolerance to sunlight.

Table 1 The effect of species fungi on larvae weight of Spodoptera litura larvae

\begin{tabular}{|l|c|c|c|c|c|c|c|}
\hline \multirow{2}{*}{ Species of fungi } & \multicolumn{6}{|c|}{ Larvae weight (g/larvae) after fungal filtrate UV treatment } \\
\cline { 2 - 9 } & $\mathbf{1}$ day & $\mathbf{3}$ days & $\mathbf{5}$ days & $\mathbf{7}$ days & $\mathbf{9}$ days & $\mathbf{1 1}$ days & $\mathbf{1 3}$ days \\
\hline Beauveria bassiana & $0.30^{\mathrm{a}}$ & 0.58 & $1.08^{\mathrm{a}}$ & $1.64^{\mathrm{a}}$ & 4.42 & 3.14 & 3.01 \\
\hline Metarhizium anisopliae & $0.38^{\mathrm{b}}$ & 0.59 & $1.19^{\mathrm{b}}$ & $1.81^{\mathrm{b}}$ & 4.31 & 3.28 & 3.53 \\
\hline ANOVA F-value & $34.56^{*}$ & $0.27^{\mathrm{ns}}$ & $8.75^{*}$ & $5.61^{*}$ & $0.52^{\mathrm{ns}}$ & $0.28^{\mathrm{ns}}$ & $2.69^{\mathrm{ns}}$ \\
\hline P value (0.05) & 0.001 & 0.61 & 0.01 & 0.02 & 0.47 & 0.60 & 0.11 \\
\hline LSD test & 0.01 & - & 0.02 & 0.03 & - & - & - \\
\hline
\end{tabular}

Note: * = significantly different; values within a column followed by the same letters were not significantly different at $\mathrm{P}<0.05$ according to LSD test, ns = not significantly different

Table 2 The effect of the intensity of UV irradiation for fungal filtrate on larvae weight of Spodoptera litura larvae

\begin{tabular}{|l|c|c|c|c|c|c|c|}
\hline \multirow{2}{*}{$\begin{array}{l}\text { Intensity of UV } \\
\text { irradiation }\end{array}$} & \multicolumn{6}{|c|}{ Larvae weight (g/larvae) after UV fungal filtrate treatment } \\
\cline { 2 - 8 } & $\mathbf{1}$ day & $\mathbf{3}$ days & $\mathbf{5}$ days & $\mathbf{7}$ days & $\mathbf{9}$ days & $\mathbf{1 1}$ days & $\mathbf{1 3}$ days \\
\hline Control (aquadest) & 0.33 & 0.61 & 1.11 & 1.66 & 4.51 & 3.24 & $3.59^{\mathrm{ab}}$ \\
\hline 0 watt & 0.34 & 0.54 & 1.08 & 1.70 & 4.76 & 3.34 & $1.39^{\mathrm{a}}$ \\
\hline $\mathbf{5}$ watts & 0.33 & 0.56 & 1.24 & 1.78 & 4.58 & 3.36 & $3.38^{\mathrm{ab}}$ \\
\hline 10 watts & 0.33 & 0.57 & 1.13 & 1.66 & 3.92 & 3.08 & $3.37^{\mathrm{ab}}$ \\
\hline 15 watts & 0.36 & 0.55 & 1.18 & 1.83 & 4.40 & 3.18 & $3.82^{\mathrm{ab}}$ \\
\hline 20 watts & 0.35 & 0.64 & 1.10 & 1.72 & 4.23 & 2.92 & $3.75^{\mathrm{ab}}$ \\
\hline 30 watts & 0.36 & 0.62 & 1.11 & 1.72 & 4.16 & 3.31 & $3.60^{\mathrm{ab}}$ \\
\hline ANOVA F-value & $0.58^{\mathrm{ns}}$ & $0.78^{\mathrm{ns}}$ & $1.44^{\mathrm{ns}}$ & $0.42^{\mathrm{ns}}$ & $0.61^{\mathrm{ns}}$ & $0.20^{\mathrm{ns}}$ & $4.07^{*}$ \\
\hline P value $(0.05)$ & 0.74 & 0.59 & 0.23 & 0.853 & 0.72 & 0.973 & 0.01 \\
\hline LSD test & - & - & - & - & - & - & 0.49 \\
\hline
\end{tabular}

Note: * = significantly different; values within a column followed by the same letters were not significantly different at $\mathrm{P}<0.05$ according to LSD test, ns = not significantly different

Table 3 The effect of fungal species and the intensity of UV irradiation for fungal filtrate on mortality and $\mathrm{LT}_{50}$ of Spodoptera litura larvae

\begin{tabular}{|l|c|c|}
\hline $\begin{array}{l}\text { Species of fungi } \mathbf{x} \text { intensity of } \\
\text { irradiation }\end{array}$ & Mortality (\%) & LT $_{\mathbf{5 0}}$ (days) \\
\hline Control (aquadest) & $0^{\mathrm{a}}$ & - \\
\hline B. bassiana $\times$ 0 watts & $97.33 \pm 2.67^{\mathrm{hi}}$ & $12.16 \pm 0.31^{\mathrm{bc}}$ \\
\hline B. bassiana $\times 5$ watts & $54.66 \pm 1.33^{\mathrm{f}}$ & $16.95 \pm 1.50^{\mathrm{bcd}}$ \\
\hline B. bassiana $\times 10$ watts & $32.00 \pm 2.31^{\mathrm{d}}$ & $20.59 \pm 3.35^{\mathrm{cd}}$ \\
\hline B. bassiana $\times 15$ watts & $30.66 \pm 4.81^{\mathrm{d}}$ & $27.85 \pm 16.37^{\mathrm{d}}$ \\
\hline B. bassiana $\times 20$ watts & $12.00 \pm 2.31^{\mathrm{c}}$ & \\
\hline
\end{tabular}


Table 3 (continuation)

\begin{tabular}{|c|c|c|}
\hline B. bassiana $\mathrm{x} 30$ watts & $4.00 \pm 2.31^{\mathrm{b}}$ & $42.66 \pm 29.80^{\mathrm{e}}$ \\
\hline Control (aquadest) & $0^{\mathrm{a}}$ & - \\
\hline M. anisopliae $\mathrm{x} 0$ watts & $96.66 \pm 4.00^{\mathrm{h}}$ & $7.62 \pm 0.20^{\mathrm{ab}}$ \\
\hline M. anisopliae x 5 watts & $68.00 \pm 4.00^{\mathrm{g}}$ & $9.24 \pm 0.34^{\mathrm{abc}}$ \\
\hline M. anisopliae x 10 watts & $50.67 \pm 35.3^{\mathrm{ef}}$ & $10.98 \pm 0.32^{\mathrm{bc}}$ \\
\hline M. anisopliae x 15 watts & $38.66 \pm 5.81^{\mathrm{de}}$ & $12.51 \pm 1.68^{\mathrm{bc}}$ \\
\hline M. anisopliae $\mathrm{x} 20$ watts & $26.60 \pm 2.67^{\mathrm{d}}$ & $15.58 \pm 1.40^{\mathrm{bc}}$ \\
\hline M. anisopliae $\mathrm{x} 30$ watts & $9.33 \pm 2,67^{\mathrm{c}}$ & $17.67 \pm 1.71^{\mathrm{bcd}}$ \\
\hline ANOVA F-value & $1.248 *$ & $4.300^{*}$ \\
\hline $\mathrm{P}$ value $(0.05)$ & 0.00 & 0.00 \\
\hline LSD test & 5.25 & 11.56 \\
\hline
\end{tabular}

Note: * significantly different; values within a column followed by the same letters were not significantly different at $\mathrm{P}<0.05$ according to LSD test, $\mathrm{ns}=$ not significantly different

\section{CONCLUSION}

Metarhizium anisopliae is more tolerant of irradiation compared to B. bassiana. This implies that $M$. anisopliae has more potential to survive in agroecosystems with relatively more intense sunlight such as in the tropical lowlands such as freshwater swamps.

\section{ACKNOWLEDGMENTS}

This study is part of the Individual National Strategic Research (PSNI) funded by the Directorate of Research and Community Service (DRPM), Directorate General for Research and Development, Ministry of Research, Technology, and Higher Education, fiscal year of 2018, Number: 093/SP2H/ LT/DRPM/IV/2018 chaired by Siti Herlinda. Special thanks to Dr. Suwandi for identification of the fungi.

\section{REFERENCES}

[1] A. Mulyani, M. Sarwani, Karakteristik dan potensi lahan suboptimal untuk pengembangan pertanian di Indonesia, J. Sumberd. Lahan. 7(1) (2013) 4755

[2] S. Herlinda, S. Yudha, R. Thalib, Species richness and abundance of spiders inhabiting rice in fresh swamps and tidal lowlands in South Sumatra, Indonesia, J. ISSAAS. 24(1) (2018) 82-93

[3] T. Karenina, S. Herlinda, C. Irsan, Y. Pujiastuti, Abundance and species diversity of predatory arthropods inhabiting rice of refuge habitats and synthetic insecticide application in freshwater swamps in South Sumatra, Indonesia, Biodeviersitas. 20(8) (2019) 2375-2387

[4] G. Prabawati, S. Herlinda, Y. Pujiastuti, The abundance of canopy arthropods in South Sumatra (Indonesia) freshwater swamp main and ratooned rice applied with bioinsecticides and synthetic insecticide, Biodiversitas. 20(10) (2019) 29212930

[5] S. Herlinda, S. R. Yusticia, C. Irsan, B. Asmara, R. Hadi, Abundance of arthropods inhabiting canopy of rice cultivated using different planting methods and varieties, J. Biopest. 12(1) (2019) 7-18

[6] A. Johari, S. Herlinda, C. Irsan, Y. Pujiastuti, Phenomenon of Thrips (Thysanoptera) attack on chili plant (Capsicum annuum), Am. J. Agric. Biol. Sci. 11(3) (2016) 103-109

[7] D. Roy, P. K. Sarkar, Field evaluation of new generation insecto-acaricides against thrips, yellow mite and fruit borer complex of Chilli, Ann. Pl. Protec. Sci. 25(1) (2017) 66-73

[8] A. Johari, S. Herlinda, Y. Pujiastuti, C. Irsan, D. Sartiami, Morphological and genetic variation of Thrips parvispinus (Thysanoptera: Thripidae) in chili plantation (Capsicum annuum L .) in the lowland and highland of Jambi Province, Indonesia, Am. J. Biosci., 2(1) (2014) 17-21

[9] R. I. Vargas, J. C. Piñero, L. Leblanc, An overview of pest species of bactrocera fruit flies (Diptera: Tephritidae) and the integration of biopesticides with other biological approaches for their management with a focus on the Pacific Region, Insects. 6 (2015) 297-318 
(2007) 237-243

[10] S. Herlinda, Spore Density and Viability of Entomopathogenic Fungal Isolates from Indonesia, and Their Virulence against Aphis gossypii Glover (Homoptera: Aphididae), Trop. Life Sci. Res. 21(1) (2010) 11-19

[11] D. R. Ayudya, S. Herlinda, S. Suwandi, Insecticidal activity of culture filtrates from liquid medium of Beauveria bassiana isolates from South Sumatra (Indonesia) wetland soil against larvae of Spodoptera litura, Biodiversitas. 20(8) (2019) 2101-2109

[12] E. Sumikarsih, S. Herlinda, Y. Pujiastuti, Conidial density and viability of Beauveria bassiana isolates from Java and Sumatra and their virulence against Nilaparvata lugens at different temperatures, Agrivita, 41(2) (2019) 335-349

[13] C. Chinniah, A. Ravikumar, M. Kalyanasundaram, and P. Parthiban, Field evaluation of Metarhizium anisopliae liquid formulation (Bio- Magic $®$ ) against brown plant hopper, Nilaparvata lugens Stal on rice, J. Biopestic. 9(2) (2016) 211-219

[14] A. Sevİm, M. Höfte, Z. Demİrbağ, Genetic variability of Beauveria bassiana and Metarhizium anisopliae var . anisopliae isolates obtained from the Eastern Black Sea Region of Turkey, Turk J Biol. 36 (2012) 255-265

[15] S. Herlinda et al., Effects of high temperature and ultraviolet-C irradiance on conidial viability and density of Beauveria bassiana and Metarhizium anisopliae isolated from soils of lowland ecosystems in Indonesia, Eurasian J. Anal. Chem. 13(6) (2018) 209-216

[16] A. Safitri, S. Herlinda, A. Setiawan, Entomopathogenic fungi of soils of freshwater swamps, tidal lowlands, peatlands, and highlands of South Sumatra, Indonesia. Biodiversitas, 19(6) (2018) 2365-2373

[17] I.M.W. Rodrigues, M.R. Forim, M.F.G.F. Silva, J.B. Fernandes, A. Filho, Effect of ultraviolet radiation on fungi Beauveria bassiana and Metarhizium anisopliae, pure and encapsulated, and bio-insecticide action on Diatraea saccharalis, Adv. Entomol. 4 (2016) 151-162

[18] L. Chelico, J.L. Haughian, A.E. Woytowich, and G.G. Khachatourians, Quantification of ultraviolet$\mathrm{C}$ irradiation induced cyclobutane pyrimidine, Mycologia, 97(3) (2005) 621-627

[19] E.K.K. Fernandes, D.E.N. Rangel, A.M. Moraes, V.R.E.P. Bittencourt, and D.W. Roberts, Variability in tolerance to UV-B radiation among Beauveria spp. isolates, J Invertebr Pathol, 96
[20] T. Y. Shin, S. M. Bae, D. J. Kim, and H. G. Yun, Evaluation of virulence, tolerance to environmental factors and antimicrobial activities of entomopathogenic fungi against two-spotted spider mite, Tetranychus urticae, Mycoscience, 58(3) (2017) 204-212 